\title{
Validation of the Diet Quality Index for Adolescents by comparison with biomarkers, nutrient and food intakes: the HELENA study
}

Krishna Vyncke ${ }^{1,2 *}$, Estefania Cruz Fernandez ${ }^{1,3}$, Marta Fajó-Pascual ${ }^{3,4}$, Magdalena Cuenca-García ${ }^{1,5}$, Willem De Keyzer ${ }^{1,6}$, Marcela Gonzalez-Gross ${ }^{7}$, Luis A. Moreno ${ }^{4}$, Laurent Beghin ${ }^{8,9}$, Christina Breidenassel ${ }^{7,10}$, Mathilde Kersting ${ }^{11}$, Ulrike Albers ${ }^{7}$, Katharina Diethelm ${ }^{11}$, Theodora Mouratidou ${ }^{4}$, Evangelia Grammatikaki ${ }^{1,12}$, Tineke De Vriendt ${ }^{1,2}$, Ascensión Marcos ${ }^{13}$, Karin Bammann ${ }^{14,15}$, Claudia Börnhorst ${ }^{15}$, Caterine Leclercq ${ }^{16}$, Yannis Manios ${ }^{12}$, Jean Dallongeville ${ }^{17}$, Carine Vereecken ${ }^{1,2}$, Lea Maes ${ }^{1}$, Wencke $\mathrm{Gwozdz}^{18}$, Myriam Van Winckel ${ }^{19}$, Frédéric Gottrand ${ }^{9}$, Michael Sjöström ${ }^{20}$, Ligia E. Díaz ${ }^{13}$, Anouk Geelen ${ }^{21}$, Lena Hallström ${ }^{20}$, Kurt Widhalm ${ }^{22}$, Anthony Kafatos $^{23}$, Denes Molnar ${ }^{24}$, Stefaan De Henauw ${ }^{1,25}$ and Inge Huybrechts ${ }^{1}$ on behalf of the HELENA consortium

${ }^{1}$ Department of Public Health, University Hospital - Block. A, 2nd floor, Ghent University, De Pintelaan 185, B-9000 Ghent, Belgium

${ }^{2}$ Research Foundation Flanders, Brussels, Belgium

${ }^{3}$ Facultad Ciencias Salud y Deporte, University of Zaragoza, Huesca, Spain

${ }^{4}$ GENUD (Growth, Exercise, Nutrition and Development) Research Group, School of Health Sciences (EUCS), University of Zaragoza, Spain

${ }^{5}$ Department of Medical Physiology, School of Medicine, Granada University, Granada, Spain

${ }^{6}$ Department of Nutrition and Dietetics, University College Ghent, Ghent, Belgium

${ }^{7}$ ImFINE Research Group, Department of Health and Human Performance, Facultad de Ciencias de la Actividad Física y del Deporte (INEF), Universidad Politécnica de Madrid, Madrid, Spain

${ }^{8}$ CIC-9301-Inserm-CHEU, IFR114, IMPRT, Centre Hospitalier, Lille, France

${ }^{9}$ Inserm U995, Faculté de médecine, Université Lille 2, Lille, France

${ }^{10}$ Institut für Ernährungs- und Lebensmittelwissenschaften-Humanernährung, Rheinische Friedrich-Wilhelms Universität, Bonn, Germany

${ }^{11}$ Research Institute of Child Nutrition Dortmund, Dortmund, Germany

${ }^{12}$ Department of Nutrition and Dietetics, Harokopio University, Athens, Greece

${ }^{13}$ Immunonutrition Research Group, Department of Metabolism and Nutrition, Institute of Food Science and Technology and Nutrition (ICTAN-CSIC), Madrid, Spain

${ }^{14}$ Institute for Public Health and Nursing Care Research, University of Bremen, Bremen, Germany

${ }^{15}$ BIPS Institute for Epidemiology and Prevention Research, Bremen, Germany

${ }^{16}$ National Research Institute on Food and Nutrition, Rome, Italy

${ }^{17}$ Inserm U744, Institut Pasteur de Lille, Université Lille Nord de France, Lille, France

${ }^{18}$ Department of Intercultural Communication and Management, Copenhagen Business School, Copenhagen, Denmark

${ }^{19}$ Department of Pediatrics and Medical Genetics, Ghent University Hospital, Ghent, Belgium

${ }^{20}$ Unit for Preventive Nutrition, Department of Biosciences and Nutrition, Karolinska Institute, Stockholm (Huddinge),

Sweden and School of Health, Care and Social Welfare Mälardalens University, Västerås, Sweden

${ }^{21}$ Division of Human Nutrition, Wageningen University, Wageningen, The Netherlands

${ }^{22}$ Division of Clinical Nutrition and Prevention, Department of Pediatrics, Medical University of Vienna, Vienna, Austria

${ }^{23}$ Preventive Medicine and Nutrition Clinic, University of Crete, Heraklion, Greece

${ }^{24}$ Department of Pediatrics, University of Pécs, Pécs, Hungary

${ }^{25}$ Department of Health Sciences, Vesalius, Hogeschool Gent, Ghent, Belgium

(Submitted 6 January 2012 - Final revision received 9 August 2012 - Accepted 14 August 2012 - First published online 30 October 2012)

Abbreviations: 25(OH)D, 25-hydroxyvitamin D; CINDI, Countrywide Integrated Non-communicable Disease Intervention; DIAT, Dietary Intake Assessment Tool; DQI, Diet Quality Index; DQI-A, DQI for Adolescents; FA, fatty acid; FBDG, Food-based dietary guideline; HELENA, Healthy Lifestyle in Europe by Nutrition in Adolescence.

*Corresponding author: K. Vyncke, fax +32933249 94, email k.vyncke@ugent.be 


\section{Abstract}

Food-based dietary guidelines (FBDG) aim to address the nutritional requirements at population level in order to prevent diseases and promote a healthy lifestyle. Diet quality indices can be used to assess the compliance with these FBDG. The present study aimed to investigate whether the newly developed Diet Quality Index for Adolescents (DQI-A) is a good surrogate measure for adherence to FBDG, and whether adherence to these FBDG effectively leads to better nutrient intakes and nutritional biomarkers in adolescents. Participants included 1804 European adolescents who were recruited in the Healthy Lifestyle in Europe by Nutrition in Adolescence (HELENA) Study. Dietary intake was assessed by two, non-consecutive $24 \mathrm{~h}$ recalls. A DQI-A score, considering the components' dietary quality, diversity and equilibrium, was calculated. Associations between the DQI-A and food and nutrient intakes and blood concentration biomarkers were investigated using multilevel regression analysis corrected for centre, age and sex. DQI-A scores were associated with food intake in the expected direction: positive associations with nutrient-dense food items, such as fruits and vegetables, and inverse associations with energy-dense and low-nutritious foods. On the nutrient level, the DQI-A was positively related to the intake of water, fibre and most minerals and vitamins. No association was found between the DQI-A and total fat intake. Furthermore, a positive association was observed with 25-hydroxyvitamin D, holo-transcobalamin and $n$-3 fatty acid serum levels. The present study has shown good validity of the DQI-A by confirming the expected associations with food and nutrient intakes and some biomarkers in blood.

\section{Key words: Diet quality index: Adolescents: HELENA study}

It is generally accepted that inadequate or excessive nutrient intake can have important health consequences, such as nutritional deficiencies, increased risk of type 2 diabetes, CVD and obesity. Food-based dietary guidelines (FBDG) have been developed to prevent such dietary-related health problems ${ }^{(1,2)}$. These guidelines are targeted at the general population and contain messages that give an indication of what a person should be eating in terms of foods rather than nutrients. These FBDG can be broad and non-specific, such as 'eat a variety of foods each day' or more targeted such as 'eat five portions of fruits and vegetables a day'. Messages may also specify the type of food, such as 'at least half of the grains consumed should be whole grains', or be meal specific such as 'eat a breakfast every day ${ }^{(2,3)}$.

Over the last decades, a number of diet quality indices, measuring adherence to such dietary guidelines, have been developed $^{(4-7)}$. The advantage of such indices is that they capture the complexity of human diets in a single value, taking into account the interactions between nutrients, food preparation methods and eating patterns ${ }^{(4,8,9)}$. In general, indices representing overall diet quality showed stronger correlations with health outcomes than individual nutrients or foods ${ }^{(7)}$.

The majority of existing indices are, however, unsuitable for children and adolescents, because their development is based on dietary recommendations for adults ${ }^{(10)}$. Nevertheless, appropriate indices for children and adolescents have been developed, based on recommendations specific for these age groups, e.g. the Youth Healthy Eating Index ${ }^{(11)}$, the Revised Children's Diet Quality Index (DQI) ${ }^{(12)}$, the DQI for Preschoolers $^{(13)}$, the Preschoolers Diet-Lifestyle Index ${ }^{(10)}$ and the Healthy Lifestyle-Diet Index ${ }^{(14)}$. However, most of these indices are calculated based on a combination of food and nutrient (e.g. cholesterol, Na) intake. This implies the need for detailed dietary information and use of food composition tables.

The purpose of the present study was to develop a DQI for Adolescents (DQI-A) calculated on food intake data only for assessing adherence to FBDG. Furthermore, the aim of the present study was to investigate whether adherence to FBDG (using the DQI-A as a proxy measure) is associated with better adherence to nutrient dietary recommendations and a better nutritional biomarker blood profile in European adolescents.

\section{Subjects and methods}

\section{Study design}

The 'Healthy Lifestyle in Europe by Nutrition in Adolescence (HELENA) - Cross Sectional Study' is a population-based multi-centre investigation of the nutritional and lifestyle status of adolescents, carried out in ten European cities (Vienna in Austria, Ghent in Belgium, Lille in France, Dortmund in Germany, Athens and Heraklion in Greece, Pécs in Hungary, Rome in Italy, Zaragoza in Spain and Stockholm in Sweden). Data were collected from October 2006 to December 2007. The purpose of the study was to obtain standardised, reliable and comparable data from a random sample of European adolescents on a broad battery of relevant nutrition and health-related parameters like dietary intake, food choices and preferences, serum indicators of lipid metabolism and glucose metabolism, vitamin and mineral status, anthropometry, physical activity, fitness and genetic markers. A detailed description of the HELENA study design and sampling procedure has been published elsewhere ${ }^{(15-17)}$.

The study population comprised adolescents, aged 12.517.5 years. Adolescents were excluded from the database a posteriori if they met one of the exclusion criteria, namely age $<12.5$ or $>17.5$ years, no measurement of weight and/ or height, completion of $<75 \%$ of the tests, participating simultaneously in another clinical trial or an acute infection during the week prior to the examination ${ }^{(16)}$. The total HELENA population consisted of 3528 eligible adolescents (52.3\% females). For the purpose of the present study, adolescents who provided data on two non-consecutive $24 \mathrm{~h}$ dietary recalls were included in the analysis, resulting in 2330 subjects. Participants from Heraklion and Pécs were excluded for these analyses, as no nutrient intake information was calculated for these two cities due to logistical problems. Underreporters were excluded for the analyses, as previous reports, using concentration biomarkers and the Triads 
method $^{(18)}$, have shown that the validity of food and nutrient intakes compared to 'true' intake was better when excluding underreporters $^{(19)}$. Exclusion of underreporters resulted in a final sample of 1804 adolescents (52.6\% females) for statistical analysis. Underreporting was considered when the individual ratio of energy intake divided by the estimated BMR was lower than $0.96^{(20)}$. The group of underreporters consisted of a slightly higher percentage of females $(57.8 \%$ compared to $52.6 \%$ in the plausible reports, $P=0.036)$ and had higher median (minimum, maximum) BMI values (22.5 (14.99, $45.63) \mathrm{kg} / \mathrm{m}^{2}$ compared to $20 \cdot 1(14 \cdot 08,40 \cdot 77) \mathrm{kg} / \mathrm{m}^{2}$ in the plausible reports; $P<0.001)$. No differences in age and DQI-A score were observed.

Blood samples were collected in a randomly selected subset of the total HELENA study population (1089 adolescents), of whom 697 provided two $24 \mathrm{~h}$ recalls. Exclusion of underreporters resulted in a final sample of 552 adolescents $(52.3 \%$ females) with biomarkers in the present study. Characteristics of adolescents for whom no biochemical parameters were obtained were compared to those included in the subanalysis. No significant differences in age, sex and BMI were observed between these two groups; however, the adolescents in the sub-analysis had higher mean values for the DQI-A compared to the total study population (52.6 (SD 15.6) and 51.3 (SD 16.5) \%, respectively, $P=0.018$ ).

The study was performed following the ethical guidelines of the Declaration of Helsinki, the Good Clinical Practice rules and the legislation regarding clinical research in human subjects in each of the participating countries. All study participants and their parents provided a signed informed consent form. The protocol was approved by the Human Research Review Committees of the institutions involved ${ }^{(21)}$.

\section{Dietary intake assessment}

Dietary intake was assessed by two non-consecutive $24 \mathrm{~h}$ recalls $^{(22)}$, comprising weekdays and weekend-days (except from Fridays and Saturdays), though not necessarily including a week and weekend-day for each individual. The $24 \mathrm{~h}$ recalls were collected by use of a computer-based self-administered tool, the HELENA-Dietary Intake Assessment Tool (DIAT). This tool was adapted from a previous version developed and validated for Flemish adolescents ${ }^{(23)}$. This assessment tool is based on six meal occasions (breakfast, morning snacks, lunch, afternoon snacks, evening meal, evening snacks) referring to the previous day. Trained dietitians assisted the adolescents to complete the $24 \mathrm{~h}$ recalls when needed. Adolescents selected autonomously all the consumed foods and beverages from a standardised food list in the HELENA-DIAT $^{(24)}$. Items not available in the list could be added by the participant at any moment. Consumed foods were translated to nutrients by use of the German Food Code and Nutrient Data Base (Bundeslebensmittelschlüssel, BLS, version II.3.1) ${ }^{(25)}$. The Multiple Source Method was used to estimate the usual dietary intake of nutrients and foods ${ }^{(26,27)}$. This statistical modelling technique takes into account within-person variability and calculates usual intakes corrected for age, sex and study centre.

\section{Diet Quality Index for Adolescents}

A previously validated DQI, originally developed for preschool-aged children ${ }^{(13)}$, was adapted for use in adolescents to measure their compliance to the Flemish FBDG $^{(28)}$. These FBDG put forward three basic principles for a healthy and balanced diet, namely dietary quality, dietary diversity and dietary equilibrium. Furthermore, the daily diet was divided into nine recommended food groups, namely (1) water, (2) bread and cereals, (3) grains and potatoes, (4) vegetables, (5) fruit, (6) milk products (7), cheese, (8) meat, fish, eggs and substitutes and (9) fat and oils. Milk products and cheese were allocated to different food groups because of the important difference in fat content. Meat and fish are considered in the same food group; because of the differences in nutrient content, the FBDG additionally recommended the consumption of fish preferably two times per week. However, as only two $24 \mathrm{~h}$ recalls were assessed, the frequency of fish consumption could not be considered separately in the DQI-A calculation. For each of the food groups, a range of recommended daily intakes, specifically for adolescents, was provided by the FBDG. The ranges in these FBDG were based upon the nutrient recommendations of the Belgian Health Council ${ }^{(29)}$ and the WHO, combined with data on habitual dietary intake in the Belgian population. These FBDG were very similar to dietary guidelines in other countries and to the CINDI pyramid (Countrywide Integrated Non-communicable Disease Intervention program) developed by the $\mathrm{WHO}^{(30)}$, making the index applicable for a European population.

The technical aspects of the calculation of the DQI-A are given in Table 1. Parallel to the FBDG, the DQI-A consisted of three components, namely quality, diversity and equilibrium.

Dietary quality expressed whether the adolescent made the optimal food quality choices within a food group and was represented by a 'preference group' (e.g. cereal/brown bread, fresh fruit, fish), an 'intermediate group' (e.g. white bread, minced meat) and a 'low-nutrient, energy-dense group' (e.g. soft drinks, sweet snacks, chicken nuggets). A comprehensive description of the allocation of food items to the different quality groups is given in Table 2 .

Dietary diversity expressed the degree of variation in the diet. This diversity component was obtained by giving points ranging from 0 to 9 when at least one serving of food of a recommended food group was consumed.

Dietary equilibrium was calculated from the difference between the adequacy component (which was the percentage of the minimum recommended intake for each of the main food groups, truncated to 1) and the excess component (which was the percentage of intake exceeding the upper level of the recommendation, truncated to 1 if larger than 1 and truncated to 0 when below 0 ; see Table 1 ). In the food group of meat, fish, eggs and substitutes, the daily intake of the total group was considered. As such, a too high consumption of meat and fish was penalised in the excess component. However, the fish consumption was granted points in the 
Table 1. Overview of the calculation of the Diet Quality Index for Adolescents (DQI-A)*

\begin{tabular}{|c|c|c|c|c|c|c|}
\hline \multicolumn{2}{|l|}{ FBDG } & \multicolumn{5}{|c|}{ DQI-A components } \\
\hline FG & $\begin{array}{l}\text { Recommended } \\
\text { daily intake }\end{array}$ & $\mathrm{DQ}$ & DD & DA & DEx & DE \\
\hline \multicolumn{7}{|l|}{ Recommended foods } \\
\hline Water & $1500-2250 \mathrm{ml}$ & & & & & \\
\hline Bread and cereal & $150-360 \mathrm{~g}$ & & & $\mathrm{DA}=$ actual intake $\mathrm{FG} /$ & & \\
\hline Potatoes and grains & $210-350 \mathrm{~g}$ & $\mathrm{DQ}=$ amount consumed & $\mathrm{DD}=1$ point for each $\mathrm{FG}$ if & minimum recommended & $\mathrm{DEx}=$ (actual intake FG - & \\
\hline Vegetables & $300-450 \mathrm{~g}$ & food item $(m) \times$ weighting & at least one serving is & $F G$ & $\begin{array}{l}\text { maximum recommended } \\
\mathrm{FG} \text { /maximum }\end{array}$ & \\
\hline Fruits & $250-375 \mathrm{~g}$ & factor & consumed & & recommended FG & \\
\hline $\begin{array}{l}\text { Milk products } \\
\text { Cheese }\end{array}$ & $\begin{array}{l}450-600 \mathrm{ml} \\
20-40 \mathrm{~g}\end{array}$ & & & $\begin{array}{l}\text { Values }>1 \text { were truncated } \\
\text { to } 1\end{array}$ & & \\
\hline \multirow[t]{3}{*}{ Meat, fish and substitutes } & $75-100 \mathrm{~g}$ & Weighting factor: & & & & \\
\hline & & $\begin{array}{l}+1 \text { 'preference group' } \\
0 \text { 'intermediate group' } \\
-1 \text { 'low-nutrient, energy- }\end{array}$ & & & & $D E=D A-D E x$ \\
\hline & $10-15 \pi$ & dense group' & & & $\begin{array}{l}\text { Values }>1 \text { were truncated } \\
\text { to } 1 ; \text { values }<0 \text { were }\end{array}$ & \\
\hline rat and olls & $10-159$ & & & & truncated to 0 & \\
\hline \multicolumn{7}{|l|}{ Non-recommended foods } \\
\hline $\begin{array}{l}\text { Sugared drinks and fruit } \\
\text { juice }\end{array}$ & $<300 \mathrm{ml}$ & & & & & \\
\hline Score of components & & $\Sigma(D Q) / \Sigma m \times 100 \%$ & $\Sigma(\mathrm{DD}) / 9 \times 100 \%$ & $\Sigma(\mathrm{DA}) / 9 \times 100 \%$ & $\Sigma(\mathrm{DEx}) / 11 \times 100 \%$ & $\Sigma(\mathrm{DE}) / 11 \times 100 \%$ \\
\hline DQI-A score & & & (Dietary quality & dietary diversity + dietary equ & ium)/3 & \\
\hline
\end{tabular}

FBDG, food-dased dietary guidelines; FG, food groups; DQ, dietary quality; DD, dietary diversity; DA, dietary adequacy; DEx, dietary excess; DE, dietary equilibrium

"Further details on 'preference group', 'intermediate group' and 'low-nutrient, energy-dense group' can be found in Table 2 . 
Table 2. Classification of food items to the different quality groups within each food group, as advised by the Flemish Food-Based Dietary Guidelines

\begin{tabular}{|c|c|c|c|}
\hline & Preference group & Intermediate group & Low-nutrient, energy-dense group \\
\hline Water & Plain water & $\begin{array}{l}\text { Non-salted, energy-poor drinks } \\
(<20.92 \mathrm{~kJ} / 100 \mathrm{ml})\end{array}$ & $\begin{array}{l}\text { High-energy drinks } \\
(>20.92 \mathrm{~kJ} / 100 \mathrm{ml}) \text {, bouillons } \\
\text { and alcoholic beverages }\end{array}$ \\
\hline Bread and cereal & $\begin{array}{l}\text { Items rich in fibre and with a low-fat } \\
\text { content (e.g. cereal bread) }\end{array}$ & $\begin{array}{l}\text { Items with a low-fibre content } \\
\text { and/or added fat (e.g. white } \\
\text { bread, raisin bread) }\end{array}$ & $\begin{array}{l}\text { High-fat preparations } \\
\text { (e.g. pies, cakes) }\end{array}$ \\
\hline Potatoes and grains & $\begin{array}{l}\text { Items rich in fibre and with a low-fat } \\
\text { content (e.g. boiled potatoes, } \\
\text { bulgur, whole-wheat pasta) }\end{array}$ & $\begin{array}{l}\text { Items with a low-fibre content } \\
\text { and/or added fat (e.g. white rice, } \\
\text { mashed potatoes) }\end{array}$ & $\begin{array}{l}\text { High-fat preparations } \\
\text { (e.g. French fries, chips) }\end{array}$ \\
\hline Vegetables & $\begin{array}{l}\text { Fresh or frozen vegetables without } \\
\text { additives }\end{array}$ & $\begin{array}{l}\text { Vegetables prepared with cream/ } \\
\text { sauces or conserved with } \\
\text { added salt }\end{array}$ & None \\
\hline Fruits & $\begin{array}{l}\text { Fresh or frozen fruits without } \\
\text { additives }\end{array}$ & Conserved and dried fruits & Jam, fruit juices \\
\hline Milk products & $\begin{array}{l}\text { Semi-skimmed or skimmed milk } \\
\text { products without added sugar } \\
\text { or sweeteners }\end{array}$ & $\begin{array}{l}\text { Sugared and whole-milk products } \\
\text { (e.g. milk or soya-based } \\
\text { puddings and desserts, } \\
\text { flavoured milk) }\end{array}$ & $\begin{array}{l}\text { Creams and desserts } \\
\text { (e.g. chocolate mousse) }\end{array}$ \\
\hline Cheese & Low-fat cheese ( $<20 \%$ fat) & Semi-fat and fat cheese & None \\
\hline $\begin{array}{l}\text { Meat, fish and } \\
\text { substitutes }\end{array}$ & Fish products and low-fat meat & $\begin{array}{l}\text { Semi-fat and fat meat products } \\
\text { (e.g. minced meat) and eggs }\end{array}$ & $\begin{array}{l}\text { Fried meat and snacks } \\
\text { (e.g. chicken nuggets) }\end{array}$ \\
\hline Fats and oils & Vegetable oils & $\begin{array}{l}\text { Margarines and lipids of mixed } \\
\text { origins }\end{array}$ & Butter and animal fats \\
\hline
\end{tabular}

quality component, as fish is always allocated to the preference group in contrast to semi-fat and fat meat products.

These three components of the DQI-A were presented in percentages. The dietary quality component ranged from -100 to $100 \%$, while dietary diversity and dietary equilibrium ranged from 0 to $100 \%$. To compute the DQI-A, the mean of these components was calculated; as such, the DQI-A ranged from -33 to $100 \%$, with higher scores reflecting a higher diet quality. The score was calculated for each day and a mean of the daily scores was taken as global index score of the individual.

\section{Blood analyses}

After an overnight fasting period, venous blood samples were drawn in the morning at school according to a standardised blood collection protocol. Details about the sampling, processing and transportation can be found elsewhere ${ }^{(31)}$. The studied biomarkers were chosen in view of clinical relevance to evaluate nutritional status (vitamin $\mathrm{D}$, vitamin $\mathrm{B}_{12}$, retinol and TAG) or as a dietary biomarker reflecting true intake (vitamin $\mathrm{C}$, plasma folate, carotenoids, $n-3$ fatty acids (FA) and trans-FA). Although plasma vitamin D concentrations are influenced by several factors such as sunlight exposure and adiposity, evidence also showed weak correlations with dietary intakes ${ }^{(32)}$. Strong correlations of dietary intakes of vitamin $\mathrm{C}$ and serum ascorbic acid concentrations have been reported mainly when habitual dietary intakes of vitamin $\mathrm{C}$ are relatively modest ${ }^{(33,34)}$. Many factors influence serum folate concentrations and bioavailability of dietary folate; however, intakes correlate moderately with serum concentrations $^{(32)}$. Weak but positive correlations were reported for males and females between dietary vitamin $B_{12}$ intake and holo-transcobalamin status, being a marker of long-term vitamin $\mathrm{B}_{12}$ status ${ }^{(35,36)}$. Weak correlations may be linked to the large size of liver vitamin $\mathrm{B}_{12}$ stores. Blood concentrations of carotenoids appear to be moderately correlated with fruit and vegetable intake ${ }^{(34,37,38)}$. Plasma retinol concentrations are only responsive to vitamin A intake in individuals with inadequate vitamin A status ${ }^{(38)}$. Plasma TAG have been shown to be positively correlated with total fat intake and negatively with fibre intake. Levels may, to some extent, be indicative of the level of dietary fibre intake, but the findings to date are conflicting ${ }^{(34,39)} . n-3$ FA intake is moderately correlated with plasma phospholipid levels, reflecting intake in the short to medium term ${ }^{(40,41)}$. Correlations between the intake of specific types of trans-FA and their levels in blood are generally good; however, correlation between the total sum of trans-FA intake and the sum of serum trans-FA levels is only weak ${ }^{(42,43)}$.

Plasma folate was measured by means of an immunoassay using the Immunolite 2000 analyser (DPC Biermann GmbH). Holo-transcobalamin (the biologically active form of vitamin $\mathrm{B}_{12}$ ) was determined by an automated microparticle enzyme immunoassay with the AxSYM analyser (Abbott Laboratories). Vitamin C, $\beta$-carotene and retinol were analysed by HPLC (Sykam) using UV detection (UV-Vis 205, Merck). Serum phospholipid FA composition was determined by capillary GC (GC-2010, FID detection, Shimadzu GmbH) after extraction performed by TLC. Serum TAG were measured enzymatically on the Dimension RxL clinical chemistry system (Dade Behring) using the manufacturer's reagents and instructions. Plasma 25-hydroxyvitamin D (25(OH)D) was analysed by ELISA using a kit (OCTEIA 25-Hydroxy Vitamin D) from Immunodiagnostic System and measured with a SunriseTM Photometer by TECAN.

\section{Statistical analysis}

Statistical analyses were performed using the statistical software PASW for Windows version 18 (SPSS, Inc.). 
Descriptive characteristics were summarised by calculating means and standard deviations for continuous variables and percentages for categorical variables. Pearson $\chi^{2}$ and $t$ tests were used to test differences between sexes in categorical and continuous variables, respectively.

Normality was evaluated visually and based on the skewness of the data distributions. Skewness of variables on intake ranged from 0.869 (meat intake) to 9.809 (alcohol intake - due to a high number of non-consumers). As these variables were studied in a large sample size ( $n$ 1804), it was considered that parametrical tests were allowed without transformations. However, variables with a skewness $>3$ were transformed (log-transformation and square root transformations were tested) and the multilevel analyses were repeated with the transformed data. For all the variables, except for $\mathrm{Na}$ intake, the results before and after transformation were similar. To facilitate the interpretation of the results, it was chosen to display the non-transformed data, except for $\mathrm{Na}$ intake which was log-transformed. The skewness of the variables on blood values ranged from $-0 \cdot 210$ to $2 \cdot 017$ and the skewness of holo-transcobalamin was $3 \cdot 110$. As these variables were only studied in a sample of 552 adolescents, it was decided to perform a log-transformation of holo-transcobalamin in order to achieve a more normal distribution. Multilevel linear regression analysis with inclusion of a random intercept for study centre was used to examine the relationship between the DQI-A and foods, nutrient intakes or blood biomarkers. Confounders (age and sex) were entered as covariates. The random intercept for centre ranged from 0.19 to $24.42 \%$, with the highest influence of centre observed for oils, butter and animal fats, and milk and yoghurt. Significant differences in mean DQI-A scores were observed between both sexes; however, results of validation were very similar. As such, results were not stratified. To adjust for multiple testing, a Bonferroni correction was applied to lower the significance level $(\alpha)$ taking into account the number of tests $(0.05 /$ number of tests). $P$ values of $0.0019,0.0013$ and 0.006 were used as thresholds of significance for the associations between DQI-A and foods, nutrients and biomarkers, respectively.

\section{Results}

The total study population consisted of 1804 participants (52.6\% females) and the mean age was 14.7 (SD 1.2) years. The DQI-A score ranged from $-11 \cdot 1$ to $84.1 \%$; the mean DQI-A scores were 49.0 (SD 17.0) and 53.3 (SD 15.9) \% for males and females, respectively $(P<0.001)$. No differences were observed in mean DQI-A between adolescents in different BMI classes or between adolescents complying with the recommendation of $60 \mathrm{~min}$ physical activity $v$. non-compliers.

Multilevel regression analysis of the DQI-A scores with the usual consumption of different foods is shown in Table 3. A strong positive association between the DQI-A score and water intake $(\mathrm{g} / \mathrm{d})$ was observed $(\beta=19.529, P<0.0001)$. In contrast, soft drinks, fruit juices and alcoholic beverages showed a significant negative association with the DQI-A. Furthermore, the DQI-A score and bread/cereals had a positive association, but there was no significant association with potatoes and grains. Milk and cheese $(\mathrm{g} / \mathrm{d})$ were positively associated with the DQI-A score, and animal fat $(\mathrm{g} / \mathrm{d})$ and vegetable fat $(\mathrm{g} / \mathrm{d})$ showed a small, however, significant positive association with the DQI-A $(\beta=0.100, \quad P<0.0001$ and $\beta=0 \cdot 118, P<0 \cdot 0001$, respectively). No significant relation was present with meat, fish, eggs and substitutes. All non-recommended (energy-dense and low-nutritious) foods showed a significant negative association with the DQI-A score.

At the level of macronutrients (Table 4), a positive association was observed between the DQI-A and water $(\mathrm{g} / \mathrm{d})$ and fibre $(\mathrm{g} / \mathrm{d})$ intake, and a negative relationship was found with total energy intake $(\mathrm{kJ} / \mathrm{d})(\beta=-2.893, P=0.0005)$. The usual intake of polysaccharides $(\mathrm{g} / \mathrm{d})$ was positively related to the dietary quality $(\beta=0.230, P=0.0004)$, whilst the intake of mono- and disaccharides $(\mathrm{g} / \mathrm{d})$ showed a negative relationship $(\beta=-0.853$ and -0.289 , respectively; both $P<0.0001)$. No significant association was seen between DQI-A and protein intake $(\mathrm{g} / \mathrm{d})$ or fat intake $(\mathrm{g} / \mathrm{d})$. All investigated minerals (Table 4), except $\mathrm{Fe}$ and $\mathrm{Cu}$, were positively associated with the DQI-A score. Furthermore, intake of almost all vitamins, except niacin, vitamin $\mathrm{C}$ and vitamin $\mathrm{E}$, showed a significant positive association with the calculated index.

Table 5 describes the results of the multilevel regression analysis between the DQI-A scores and nutritional biomarkers in a subgroup of 552 adolescents. Only for plasma 25(OH)D and holo-transcobalamin, a significant positive association was observed with the index score. The positive association with the $n-3$ FA status $(\mu \mathrm{mol} / \mathrm{l})$ was borderline significant $(\beta=0 \cdot 376, P=0.007)$.

\section{Discussion}

Diet quality indices are valuable tools to obtain a global assessment of the dietary quality of a person or population. The present study aimed to investigate whether the developed DQI-A, calculated solely from food items, was an adequate proxy measure for adherence to the FBDG. This was done by comparing the DQI-A scores with the usual intake of different foods, of which some were not included in the calculation. The results showed that DQI-A scores were significantly associated with most food items in the expected direction. Nutrient-dense food items, such as fruits and vegetables, were positively associated, whilst non-recommended foods showed negative associations. No significant relation between the DQI-A score and the usual intake of meat, fish, eggs or their substitutes was found. This was due to the fact that this food group (calculated as the sum of meat, fish and eggs) was often consumed in excess, resulting in a lower score of the dietary equilibrium component. However, it is noteworthy that the overconsumption of this food group is mainly due to an excessive intake of meat products rather than fish or meat substitutes. Fish is only over-consumed in a minority of the adolescents (twenty-six of the 1804 adolescents had a habitual fish consumption of $>100 \mathrm{~g} / \mathrm{d}$; range $0-328 \mathrm{~g} / \mathrm{d}$ ). Consumption of meat substitutes ranged from 0 to $143 \mathrm{~g} / \mathrm{d}$, with eight adolescents consuming more than $100 \mathrm{~g} / \mathrm{d}$. Furthermore, a positive relation was observed between the DQI-A score 
Table 3. Association between Diet Quality Index for Adolescents (DQI-A) scores and food intake ( $\beta$-Coefficients and $95 \%$ confidence intervals)

\begin{tabular}{|c|c|c|c|}
\hline & \multicolumn{3}{|c|}{ DQI-A ( $n$ 1804) } \\
\hline & $\beta$ & $95 \% \mathrm{Cl}$ & $P$ \\
\hline \multicolumn{4}{|l|}{ Beverages } \\
\hline Water $(\mathrm{g} / \mathrm{d})$ & 19.529 & $18 \cdot 298,20 \cdot 761$ & $<0.0001$ \\
\hline Coffee and tea $(\mathrm{g} / \mathrm{d})$ & 0.084 & $-0.243,0.412$ & 0.6137 \\
\hline Soups/bouillon (g/d) & -0.016 & $-0.213,0.182$ & 0.8777 \\
\hline \multicolumn{4}{|l|}{ Bread and cereals } \\
\hline Bread and rolls $(\mathrm{g} / \mathrm{d})$ & 0.494 & $0.330,0.658$ & $<0.0001$ \\
\hline Breakfast cereals $(\mathrm{g} / \mathrm{d})$ & 0.239 & $0.177,0.301$ & $<0.0001$ \\
\hline \multicolumn{4}{|l|}{ Potatoes and grains } \\
\hline Rice and other grains (g/d) & 0.008 & $-0.110,0.126$ & 0.8961 \\
\hline Starch roots, potatoes $(\mathrm{g} / \mathrm{d})$ & 0.063 & $-0.062,0.188$ & 0.3247 \\
\hline Pasta $(\mathrm{g} / \mathrm{d})$ & 0.254 & $0.094,0.414$ & 0.0019 \\
\hline Vegetables $(\mathrm{g} / \mathrm{d})$ & 0.911 & $0.740,1.083$ & $<0.0001$ \\
\hline Fruits $(g / d)$ & $2 \cdot 181$ & $1 \cdot 883,2.479$ & $<0.0001$ \\
\hline \multicolumn{4}{|l|}{ Milk products } \\
\hline Milk, yoghurt and milk beverages $(\mathrm{g} / \mathrm{d})$ & $4 \cdot 257$ & $3.669,4.845$ & $<0.0001$ \\
\hline Desserts and puddings milk based (g/d) & -0.069 & $-0.148,0.010$ & 0.0883 \\
\hline Cheese $(g / d)$ & 0.224 & $0.159,0.289$ & $<0.0001$ \\
\hline \multicolumn{4}{|l|}{ Meat/fish/eggs/meat alternatives } \\
\hline Meat $(g / d)$ & -0.004 & $-0.202,0.194$ & 0.9687 \\
\hline Fish products $(\mathrm{g} / \mathrm{d})$ & 0.074 & $0.001,0.146$ & 0.0466 \\
\hline Eggs $(g / d)$ & -0.005 & $-0.055,0.044$ & 0.8380 \\
\hline Meat substitutes, nuts and pulses ( $\mathrm{g} / \mathrm{d}$ ) & 0.124 & $0.023,0.224$ & 0.0160 \\
\hline \multicolumn{4}{|l|}{ Fat and oil } \\
\hline Margarine and vegetable oils (g/d) & 0.118 & $0.083,0.153$ & $<0.0001$ \\
\hline Butter and animal fats $(\mathrm{g} / \mathrm{d})$ & $0 \cdot 100$ & $0.065,0.136$ & $<0.0001$ \\
\hline \multicolumn{4}{|l|}{ Non-recommended foods } \\
\hline \multicolumn{4}{|l|}{ Snacks and candy } \\
\hline Cakes, pies, biscuits (g/d) & -0.287 & $-0.409,-0.166$ & $<0.0001$ \\
\hline Savoury snacks $(g / d)$ & -0.245 & $-0.295,-0.195$ & $<0.0001$ \\
\hline Sugar, honey, jam, candies, chocolate $(\mathrm{g} / \mathrm{d})$ & -0.281 & $-0.404,-0.158$ & $<0.0001$ \\
\hline Sauces and creams $(\mathrm{g} / \mathrm{d})$ & -0.143 & $-0.225,-0.062$ & 0.0006 \\
\hline \multicolumn{4}{|l|}{ Drinks } \\
\hline Carbonated/soft/isotonic drinks (g/d) & -11.456 & $-12 \cdot 188,-10 \cdot 724$ & $<0.0001$ \\
\hline Fruit and vegetable juices $(\mathrm{g} / \mathrm{d})$ & -3.133 & $-3.588,-2.677$ & $<0.0001$ \\
\hline Alcoholic beverages $(\mathrm{g} / \mathrm{d})$ & -0.798 & $-1.065,-0.531$ & $<0.0001$ \\
\hline
\end{tabular}

* Multilevel regression analyses with inclusion of a random intercept for centre and corrected for age and sex as independent variables. Bonferroni correction resulted in level of significance $<0.0019$.

and the consumption of fat and oils. A moderate intake of fat and oil is recommended in the Flemish FBDG. Also, a high consumption of vegetable oils is in line with the Mediterranean diet and the FBDG of Greece and Spain ${ }^{(30)}$. Moreover, adherence to the Mediterranean diet has been shown to have beneficial effects on cardiovascular risk factors ${ }^{(44)}$. In the past, it was generally assumed that saturated fats induced a higher risk of CVD; however, this has been questioned lately, as replacement of SFA with refined carbohydrates was suspected to increase the risk of $\operatorname{CVD}^{(45,46)}$. Furthermore, children and adolescents have higher lipid intake needs, which is essential for growth. Besides energy delivery, lipids have an important function as structural components in all tissues, because they are indispensable for cell and plasma membrane synthesis ${ }^{(47)}$.

Another interesting fact was the inverse relationship between the DQI-A score and energy intake. This suggested that adolescents with large, excessive food intake, and thus more likely to meet minimal intake recommendations, did not necessarily obtain a higher diet quality score. This was in contrast with other DQI validation studies where participants consuming more food, and thus more total energy, had higher quality scores compared with adolescents who ate less ${ }^{(11,48)}$.

In the development of the DQI-A, three other variants have been studied, namely, one with inclusion of a measure for meal frequency, one with inclusion of a measure of physical activity and both (data not shown). The DQI-A, as described in the present paper, however, showed the strongest associations with the different food items as well as the largest variance between individuals. Overall, based on these results, it can be concluded that the DQI-A is indeed a good surrogate marker for adherence to FBDG.

The second aim of the present study was to investigate whether adherence to these FBDG, using the DQI-A as a proxy measure, resulted in a better nutritional intake and blood biomarker profile. Indeed, the DQI-A was strongly related to higher intakes of water, fibre and most minerals and vitamins. The high fibre intake was a clear representation of the FBDG to consume sufficient vegetables and fruits, and to choose wholegrain products ${ }^{(28)}$. Also, the DQI-A was positively associated with complex carbohydrates, whilst the usual intake of mono- and disaccharides decreased with better 
Table 4. Associations between Diet Quality Index for Adolescents (DQI-A) score and usual intake of macro- and micronutrients*

( $\beta$-Coefficients and $95 \%$ confidence intervals)

\begin{tabular}{|c|c|c|c|}
\hline & \multicolumn{3}{|c|}{ DQI-A (n 1804) } \\
\hline & $\beta$ & $95 \% \mathrm{Cl}$ & $P$ \\
\hline \multicolumn{4}{|l|}{ Macronutrients } \\
\hline Energy (kJ/d) & $-12 \cdot 104$ & $-18 \cdot 886,-5 \cdot 317$ & 0.0005 \\
\hline Protein $(\mathrm{g} / \mathrm{d})$ & 0.119 & $0.043,0.195$ & 0.0020 \\
\hline Carbohydrates (g/d) & -0.836 & $-1.072,-0.599$ & $<0.0001$ \\
\hline Total fat $(\mathrm{g} / \mathrm{d})$ & 0.044 & $-0.034,0.123$ & 0.2643 \\
\hline Water $(\mathrm{g} / \mathrm{d})$ & $10 \cdot 646$ & $8.952,12.339$ & $<0.0001$ \\
\hline Fibre $(\mathrm{g} / \mathrm{d})$ & $0 \cdot 107$ & $0.088,0.125$ & $<0.0001$ \\
\hline \multicolumn{4}{|l|}{ Carbohydrates } \\
\hline Monosaccharides $(\mathrm{g} / \mathrm{d})$ & -0.853 & $-939 \cdot 141,-766.813$ & $<0.0001$ \\
\hline Disaccharides $(\mathrm{g} / \mathrm{d})$ & -0.289 & $-405.958,-171 \cdot 109$ & $<0.0001$ \\
\hline Polysaccharides $(\mathrm{g} / \mathrm{d})$ & 0.230 & 103.602, 357.275 & 0.0004 \\
\hline \multicolumn{4}{|l|}{ Fats } \\
\hline SFA (mg/d) & 37.695 & $2 \cdot 810,72 \cdot 580$ & 0.0342 \\
\hline MUFA (mg/d) & 32.993 & $3 \cdot 639,62 \cdot 348$ & 0.0276 \\
\hline PUFA (mg/d) & $-17 \cdot 256$ & $-31.941,-2.570$ & 0.0213 \\
\hline Cholesterol (mg/d) & 0.333 & $-0.017,0.684$ & 0.0624 \\
\hline \multicolumn{4}{|l|}{ Minerals } \\
\hline $\mathrm{Na}(\mathrm{mg} / \mathrm{d}) \dagger$ & 1.003 & $1.002,1.005$ & $<0.0001$ \\
\hline $\mathrm{K}(\mathrm{mg} / \mathrm{d})$ & $7 \cdot 687$ & $5 \cdot 226,10 \cdot 147$ & $<0.0001$ \\
\hline $\mathrm{Cl}(\mathrm{mg} / \mathrm{d})$ & 8.583 & $5.531,11.635$ & $<0.0001$ \\
\hline $\mathrm{Ca}(\mathrm{mg} / \mathrm{d})$ & $6 \cdot 623$ & $5 \cdot 549,7 \cdot 697$ & $<0.0001$ \\
\hline $\mathrm{Mg}(\mathrm{mg} / \mathrm{d})$ & 0.923 & $0.653,1.192$ & $<0.0001$ \\
\hline $\mathrm{Fe}(\mu \mathrm{g} / \mathrm{d})$ & -6.848 & $-17 \cdot 827,4 \cdot 132$ & 0.2213 \\
\hline $\mathrm{Cu}(\mu \mathrm{g} / \mathrm{d})$ & 2.793 & $0.957,4.630$ & 0.0029 \\
\hline $\mathrm{Zn}(\mu \mathrm{g} / \mathrm{d})$ & 38.728 & $30.434,47.023$ & $<0.0001$ \\
\hline$F(\mu \mathrm{g} / \mathrm{d})$ & $2 \cdot 247$ & $1.557,2.937$ & $<0.0001$ \\
\hline $\mathrm{I}(\mu \mathrm{g} / \mathrm{d})$ & 0.595 & $0.500,0.691$ & $<0.0001$ \\
\hline$P(\mathrm{mg} / \mathrm{d})$ & $5 \cdot 363$ & $4.233,6.494$ & $<0.0001$ \\
\hline$M n(\mu \mathrm{g} / \mathrm{d})$ & 11.073 & $6.669,15.477$ & $<0.0001$ \\
\hline \multicolumn{4}{|l|}{ Vitamins } \\
\hline Thiamine $(\mu \mathrm{g} / \mathrm{d})$ & 1.947 & $0.848,3.045$ & 0.0005 \\
\hline Riboflavin ( $\mu \mathrm{g} / \mathrm{d})$ & 7.936 & $6.452,9.420$ & $<0.0001$ \\
\hline $\operatorname{Niacin}(\mu \mathrm{g} / \mathrm{d})$ & $17 \cdot 818$ & $2 \cdot 495,33 \cdot 140$ & 0.0227 \\
\hline Pantothenic acid $(\mu \mathrm{g} / \mathrm{d})$ & $18 \cdot 807$ & $14.547,23.066$ & $<0.0001$ \\
\hline Pyridoxine $(\mu \mathrm{g} / \mathrm{d})$ & $4 \cdot 140$ & $2 \cdot 556,5.723$ & $<0.0001$ \\
\hline Biotin $(\mu \mathrm{g} / \mathrm{d})$ & $0 \cdot 171$ & $0.133,0.209$ & $<0.0001$ \\
\hline Total folic acid $(\mu \mathrm{g} / \mathrm{d})$ & 0.699 & $0.511,0.887$ & $<0.0001$ \\
\hline Cobalamin $(\mu \mathrm{g} / \mathrm{d})$ & 0.020 & $0.013,0.027$ & $<0.0001$ \\
\hline Vitamin C $(\mathrm{g} / \mathrm{d})$ & 0.169 & $-0.007,0.345$ & 0.0601 \\
\hline Retinol equivalents $(\mu \mathrm{g} / \mathrm{d})$ & 5.075 & $3.713,6.436$ & $<0.0001$ \\
\hline Vitamin $D(\mu \mathrm{g} / \mathrm{d})$ & 0.005 & $0.002,0.008$ & 0.0006 \\
\hline Vitamin $E(\mu \mathrm{g} / \mathrm{d})$ & $2 \cdot 813$ & $-6.578,12.204$ & 0.5569 \\
\hline Vitamin $\mathrm{K}(\mu \mathrm{g} / \mathrm{d})$ & 1.064 & $0.812,1.317$ & $<0.0001$ \\
\hline
\end{tabular}

* Multilevel regression analysis with inclusion of a random intercept for centre and corrected for age and sex as independent variables. Bonferroni correction resulted in level of significance $<0.0013$. † Variable was log-transformed to obtain a normal distribution.

adherence to the guidelines, as would be expected ${ }^{(28,49)}$. Increased consumption of simple carbohydrate-rich foods has been associated with obesity, type 2 diabetes and the metabolic syndrome ${ }^{(49,50)}$. The absence of association with vitamin $\mathrm{C}$ intake might be attributed to the fact that vitamin $\mathrm{C}$ is prevalent in fruit juices, which are considered as non-recommended foods because of their high energy density. As such, high intakes of these items, and thus vitamin $\mathrm{C}$, resulted in a lower DQI-A, whilst a high intake of fruits and vegetables, and thus also vitamin $\mathrm{C}$, tended to increase the DQI-A. Furthermore, the lack of association of Fe and niacin with the adherence to FBDG could be due to the high concentration of these nutrients in meat products, whilst this food group showed no association with the DQI-A. In the present study population, no association could be found between the DQI-A score and the absolute intake of fat and FA. This might be due to the fact that meat was the largest contributor to fat intake, followed by non-recommended foods and dairy products ${ }^{(51)}$. As such, the 'penalisation' for the excessive intake of meat and non-recommended foods is counteracted by the recommended intake of dairy products. Also, associations might be attenuated due to faults that may arise through linkage with food composition tables. Of course, this finding might also indicate that the present FBDG are well tuned to the micronutrient recommendations, but that the guidelines are not efficient in transferring the recommendations for fats and FA. 
Table 5. Associations between the Diet Quality for Adolescents (DQI-A) scores and nutritional biomarkers ${ }^{\star}$ ( $\beta$-Coefficients and $95 \%$ confidence intervals)

\begin{tabular}{lrrr}
\hline & \multicolumn{3}{c}{ DQI-A $(n 552)$} \\
\cline { 2 - 4 } & \multicolumn{1}{c}{$\beta$} & \multicolumn{1}{c}{$95 \% \mathrm{Cl}$} & \multicolumn{1}{c}{$P$} \\
\hline Vitamin D (nmol/l) & 0.301 & $0.164,0.438$ & $<0.0001$ \\
Vitamin C $(\mathrm{mg} / \mathrm{l})$ & 0.125 & $-0.058,0.309$ & 0.1807 \\
Plasma folate $(\mathrm{nmol} / \mathrm{l})$ & 0.051 & $-0.007,0.109$ & 0.0826 \\
Holo-transcobalamin & 1.005 & $1.002,1.007$ & 0.0002 \\
$\quad(T C-I / \mathrm{B} 12)(\mathrm{pmol} / \mathrm{l}) \dagger$ & & & \\
$\beta$-Carotene $(\mathrm{ng} / \mathrm{ml})$ & 0.608 & $-0.445,1.661$ & 0.2570 \\
Retinol $(\mathrm{ng} / \mathrm{ml})$ & 0.310 & $-0.285,0.905$ & 0.3062 \\
TAG $(\mathrm{mg} / \mathrm{l})$ & -0.563 & $-2.308,1.181$ & 0.5259 \\
n-3 Fatty acids $(\mu \mathrm{mol} / \mathrm{l})$ & 0.376 & $0.105,0.646$ & 0.0066 \\
trans-Fatty acids $(\mu \mathrm{mol} / \mathrm{l})$ & -0.005 & $-0.010,-0.001$ & 0.0250 \\
\hline
\end{tabular}

* Multilevel regression analyses with inclusion of a random intercept for centre and corrected for age and sex as independent variables. Bonferroni correction resulted in level of significance $<0.006$.

† Variable was log-transformed to obtain a normal distribution.

Previously, it has been shown that biomarkers do not always perform better than food intake assessment methods to evaluate true nutrient intake ${ }^{(52)}$. Moreover, not all nutrients have well-defined biological markers and many are influenced by other factors than intake. In the present study population, a positive association was found between the DQI-A and levels of $25(\mathrm{OH}) \mathrm{D}$ and holo-transcobalamin, representing the bioactive fraction of vitamin $\mathrm{B}_{12}$, and $n-3$ FA. Amongst others, plasma levels of $25(\mathrm{OH}) \mathrm{D}$ are related to a better bone mineralisation ${ }^{(53)}$, while deficiency has been linked to the pathogenesis of several disorders, including cancer, hypertension, multiple sclerosis and diabetes ${ }^{(54)}$. Adequate folate and vitamin $\mathrm{B}_{12}$ levels are essential for good growth and development of the central nervous system in fetal and infant life ${ }^{(55)}$. Both folate and vitamin $\mathrm{B}_{12}$ are also essential for the synthesis of nucleotide precursors, so if both are deficient, this can result in impaired cell division and anaemia $^{(56)}$. In addition, deficiencies in folate and vitamin $\mathrm{B}_{12}$ result in high values of homocysteine in blood and tissues, which in turn is associated with organ dysfunction in children that may lead to disease later in life, such as $\mathrm{CVD}^{(16,57)}$. Also, trans-FA levels showed an inverse relation with the DQI-A, which supports the recommendation of discouraging transFA intake in the human diet because of their association with an increased cardiovascular risk ${ }^{(58)}$. This finding was, however, not significant at the corrected level of $P<0.006$.

The aim of the DQI-A was to obtain a measure for overall dietary quality of an individual. In the present study, statistically significant associations were only found with biomarkers representing long-term dietary intake $(25(\mathrm{OH}) \mathrm{D}$ and holotranscobalamin), whilst no statistically significant relationship was seen with biomarkers representing short- to mediumterm intake. This might indicate that the DQI-A is a valid measure for long-term dietary habits. Also, the associations with the other biomarkers might be attenuated, as supplement use was not taken into account in the present study.

Several diet quality indices have been associated with specific nutrient intakes and plasma biomarkers. Comparison is difficult as different statistical approaches have been applied. Similar to the present results, Hann et al. ${ }^{(59)}$ found significant positive associations between the Healthy Eating Index and vitamin $\mathrm{C}$, folate and fibre intake in a sample of adult women. In contrast to the present results, carbohydrates and total energy were also positively associated. Also Newby et $a l .{ }^{(60)}$ found significant associations between the DQIRevised and intakes of several vitamins and minerals. In contrast to the present results, however, total fat and saturated fat were negatively correlated with the index. However, in this index, low total fat intake and low saturated fat intake were incorporated as two of the ten separate components in the calculation.

Both the Healthy Eating Index and the DQI-Revised showed significant correlations with $\beta$-carotene serum values $(r$ 0.12$0 \cdot 42)^{(59-61)}$. Furthermore, Weinstein et al. ${ }^{(61)}$ found significant, but generally weak, correlations between the Healthy Eating Index and serum vitamin $\mathrm{C}(r 0.21)$, serum folate $(r 0 \cdot 15)$, serum vitamin $\mathrm{B}_{12}(r 0.01)$, serum retinol $(r 0.05)$ and serum TAG $(r 0.06)$ in a large study population $(n>16000)$. Moreover, Neuhouser et al. ${ }^{(62)}$ could not observe any correlation between the DQI and long-chain $n-3$ phospholipid FA in a sample of 102 women, whilst Gerber et al. ${ }^{(63)}$ found a significant association with $n$ - 3 erythrocyte FA. Both studies could not observe a relationship with serum $\beta$-carotene.

\section{Strengths and limitations}

This was the first study to investigate the use and validity of a DQI in a European adolescent population. In the HELENA study, all data were collected according to standardised protocols and strict procedures. Furthermore, in contrast to many other diet quality indices, the DQI-A in the present study was not based on nutrient intakes, avoiding the limitations that coincide with the use of food composition data (such as the use of various tables in different countries with different methods of analysis used, unavailability of food items, loss of dietary information from mixed dishes, etc.).

A possible limitation of the present study is the observed significant differences in sex distribution and BMI between underreporters and non-underreporters. This differential underreporting could most probably attenuate the present results, as generally it would be expected that adolescents with a higher BMI would have a less healthy dietary pattern. Underreporting by these adolescents might, however, result in better DQI-A scores than that in reality. This could attenuate the present results, especially the associations with the biomarkers. Therefore, it was chosen to exclude the underreporters. This decision was supported by a previous evaluation of food and nutrient intake assessment in the HELENA study population ${ }^{(19)}$, showing better correlations with the 'true intake' (calculated with the Triads method ${ }^{(18)}$ ) after exclusion of underreporters. However, underreporting cannot be fully precluded, as exclusion was only applied for adolescents indicating a negative energy balance. As such, attenuation of results might still be present.

The developed DQI-A score was based on the Flemish FBDG, whilst large variation in dietary habits was observed 
in the studied population. These guidelines were selected as the basis of the index score because of the great similarities with the CINDI pyramid developed by the WHO. The Flemish guidelines, however, are more specific concerning quality of different food items and recommended quantities. Compared to dietary guidelines of the other European countries, rather minor differences were found ${ }^{(30)}$. The French and Austrian guidelines put greater emphasis on vegetables $v$. cereal intake compared to the Flemish. Furthermore, daily olive oil consumption is a specific recommendation in the Greek and Spanish guidelines. Given the large similarities on the most important aspects of the dietary guidelines, the authors considered it appropriate to apply the Flemish guidelines to a European population.

The DQI-A was calculated based on two self-administered, computer-assisted, non-consecutive $24 \mathrm{~h}$ recalls. Following recommendations of the 'European Food Consumption Survey method', $24 \mathrm{~h}$ recalls were preferred as these are open-ended questionnaires from which detailed information can be obtained. Furthermore, they are applicable in large populations of different ethnicity, and standardisation is possible by self-administered computer-assisted recall methods with pictures for portion sizes ${ }^{(22,64)}$. According to Biro et $a l .^{(22)}$, the $24 \mathrm{~h}$ recall method is appropriate to assess both acute and usual intake on the individual level by repeated short-term measurements and modelling.

A limitation of the method used is, however, that only information of $2 \mathrm{~d}$ was obtained. Although this allows inclusion of exceptional intakes at the individual level, this effect is neutralised by the large number of observations. The $24 \mathrm{~h}$ dietary recall method does not allow quantifying proportions of non-consumers for particular food items, especially for infrequently consumed foods. In order to decrease this influence, nutrient intakes were corrected for within-person variability by applying the Multiple Source Method. Moreover, accuracy of collected data relies on the individual's ability to remember foods and beverages consumed in the past $24 \mathrm{~h}$, and might, therefore, be biased towards underreporting. In this respect, the $24 \mathrm{~h}$ dietary recalls were performed through the computer-assisted HELENA-DIAT program ${ }^{(24)}$ to standardise the recall procedures as much as possible. Another limitation of the use of $24 \mathrm{~h}$ recall interviews is the potential loss of dietary information from mixed dishes, as food ingredients were sometimes counted from mixed dishes.

The same food composition table for conversion of food intake data to estimated nutrient intakes was used for all survey centres. In this way, differences in definitions, analytical methods, units and modes of expression were overcome. In this regard, the German food composition tables (Bundeslebensmittelschlüssel, BLS) were chosen. The BLS is based on German, American, English, Swedish, Danish and Dutch food composition tables, on analytical values of food producing firms, publications and research results of the Federal Research Centres and Universities ${ }^{(65)}$. The BLS includes about 11000 raw and cooked foods and recipes, and has been widely used in epidemiological studies ${ }^{(66)}$.

\section{Conclusion}

The present study has shown good validity of the DQI-A by confirming the expected associations with food and nutrient intakes and some biomarkers in blood. However, further investigation is necessary to explore why the present guidelines do not reach their goal of obtaining a more favourable lipid intake with increasing DQI-A scores.

\section{Acknowledgements}

The HELENA study has taken place with the financial support of the European Community Sixth RTD Framework Programme (Contract FOOD-CT-2005-007034). There was additional support from the Spanish Ministry of Education (AGL2007-29784-E/ALI), Axis-Shield Diagnostics Limited (Oslo, Norway), Abbot Científica S.A. (Spain) and Cognis GmbH (Germany). K. V., T. D. V. and C. V. are financially supported by the Research Foundation Flanders. U. A. is financially supported by the Universidad Politécnica de Madrid. The content of the present article reflects only the authors' views and the European Community is not liable for any use that may be made of the information contained therein. Many thanks to Christel Bierschbach, Adelheid Schuch, Anke Berchtold, Petra Pickert, Andre Spinneker and Anke Carstensen for their contribution to the laboratory work. L. A. M., M. K., A. M., Y. M., M. G.-G., J. D., L. M., F. G., M. S., A. K., D. M., K. W., C. L. and S. D. H. designed the research. I. H. performed the data cleaning, K. V. and E. C. F. did the statistical analysis. K. V., M. F.-P., M. C.-G., W. D. K., T. M., T. D. V., C. B., K. B., C. V. and I. H. wrote the paper and L. B., C. B., U. A., K. D., E. G., W. G., M. V. W., L. E. D., A. G. and L. H. edited the manuscript. K. V. had primary responsibility for the final content. All authors read and approved the final manuscript. None of the authors had a personal or financial conflict of interest. The authors declare not having any conflicts of interest.

\section{References}

1. Food and Agriculture Organization of the United Nations/ World Health Organization (1996) Preparation and Use of Food-based Dietary Guidelines. Report of a Joint FAO/WHO Consultation. Nicosia: WHO.

2. Sandstrom B (2001) A framework for food-based dietary guidelines in the European Union. Public Health Nutr 4 , 293-305.

3. World Health Organization (2000) Obesity: Preventing and Managing the Global Epidemic. WHO Technical Report Series no. 894. Geneva: WHO

4. Waijers PM, Feskens EJ \& Ocke MC (2007) A critical review of predefined diet quality scores. BrJ Nutr 97, 219-231.

5. Patterson RE, Haines PS \& Popkin BM (1994) Diet quality index: capturing a multidimensional behavior. $J$ Am Diet Assoc 94, 57-64.

6. Kennedy ET, Ohls J, Carlson S, et al. (1995) The Healthy Eating Index: design and applications. J Am Diet Assoc 95, 1103-1108.

7. Kant AK (1996) Indexes of overall diet quality: a review. J Am Diet Assoc 96, 785-791. 
8. Kant AK (2004) Dietary patterns and health outcomes. J Am Diet Assoc 104, 615-635.

9. Hu FB (2002) Dietary pattern analysis: a new direction in nutritional epidemiology. Curr Opin Lipidol 13, 3-9.

10. Manios Y, Kourlaba G, Grammatikaki E, et al. (2010) Development of a diet-lifestyle quality index for young children and its relation to obesity: the Preschoolers Diet-Lifestyle Index. Public Health Nutr 13, 2000-2009.

11. Feskanich D, Rockett HR \& Colditz GA (2004) Modifying the Healthy Eating Index to assess diet quality in children and adolescents. J Am Diet Assoc 104, 1375-1383.

12. Kranz S, Findeis JL \& Shrestha SS (2008) Use of the Revised Children's Diet Quality Index to assess preschooler's diet quality, its sociodemographic predictors, and its association with body weight status. J Pediatr (Rio J) 84, 26-34.

13. Huybrechts I, Vereecken C, De Bacquer D, et al. (2010) Reproducibility and validity of a diet quality index for children assessed using a FFQ. Br J Nutr 104, 135-144.

14. Manios Y, Kourlaba G, Grammatikaki E, et al. (2010) Development of a lifestyle-diet quality index for primary schoolchildren and its relation to insulin resistance: the Healthy Lifestyle-Diet Index. Eur J Clin Nutr 64, 1399-1406.

15. De Henauw S, Gottrand F, De Bourdeaudhuij I, et al. (2007) Nutritional status and lifestyles of adolescents from a public health perspective. The HELENA Project - Healthy Lifestyle in Europe by Nutrition in Adolescence. J Public Health 15, $187-197$.

16. Moreno LA, González-Gross M, Kersting M, et al. (2008) Assessing, understanding and modifying nutritional status, eating habits and physical activity in European adolescents: The HELENA (Healthy Lifestyle in Europe by Nutrition in Adolescence) Study. Public Health Nutr 11, 288-299.

17. Moreno LA, De Henauw S, González-Gross M, et al. (2008) Design and implementation of the Healthy Lifestyle in Europe by Nutrition in Adolescence Cross-Sectional Study. Int J Obes (Lond) 32, Suppl. 5, S4-S11.

18. Kaaks RJ (1997) Biochemical markers as additional measurements in studies of the accuracy of dietary questionnaire measurements: conceptual issues. Am J Clin Nutr 65 , 1232S-1239S.

19. Vandevijvere S, Geelen A, Gonzalez-Gross M, et al. (2012) Evaluation of food and nutrient intake assessment using concentration biomarkers in European adolescents from the HELENA study. Br J Nutr 109, 736-747.

20. Black AE (2000) Critical evaluation of energy intake using the Goldberg cut-off for energy intake:basal metabolic rate. A practical guide to its calculation, use and limitations. Int J Obes Relat Metab Disord 24, 1119-1130.

21. Beghin L, Castera M, Manios Y, et al. (2008) Quality assurance of ethical issues and regulatory aspects relating to good clinical practices in the HELENA Cross-Sectional Study. Int J Obes (Lond) 32, Suppl. 5, S12-S18.

22. Biro G, Hulshof KF, Ovesen L, et al. (2002) Selection of methodology to assess food intake. Eur J Clin Nutr 56, Suppl. 2, S25-S32.

23. Vereecken CA, Covents M, Matthys C, et al. (2005) Young adolescents' nutrition assessment on computer (YANA-C). Eur J Clin Nutr 59, 658-667.

24. Vereecken CA, Covents M, Sichert-Hellert W, et al. (2008) Development and evaluation of a self-administered computerized 24-h dietary recall method for adolescents in Europe. Int J Obes (Lond) 32, Suppl. 5, S26-S34.

25. Dehne LI, Klemm C, Henseler G, et al. (1999) The German Food Code and Nutrient Data Base (BLS II.2). Eur $J$ Epidemiol 15, 355-359.
26. Haubrock J, Hartigg U, Souverein O, et al. (2010) An improved statistical tool for estimating usual intake distributions: the Multiple Source Method (MSM). Arch Public Health 68, 14-15.

27. The Multiple Source Method (MSM) (2011) https://nugo. dife.de/msm (accessed September 2011).

28. VIG (2006) De actieve voedingsdriehoek: een praktische voedings- en beweeggids (The Active Food Pyramid: A Practical Guide to Diet and Physical Activity). Brussels: Vlaams Instituut voor Gezondheidspromotie (VIG).

29. Belgian Health Council (2009) Voedingsaanbevelingen voor België. Herziene versie 2009 (Nutritional Recommendations for Belgium. Revised Version 2009). Brussels: Belgian Health Council.

30. The European Food Information Council (EUFIC) (2011) http://www.eufic.org/article/en/page/RARCHIVE/expid/ food-based-dietary-guidelines-in-europe/ (accessed September 2011).

31. Gonzalez-Gross M, Breidenassel C, Gomez-Martinez S, et al. (2008) Sampling and processing of fresh blood samples within a European multicenter nutritional study: evaluation of biomarker stability during transport and storage. Int $J$ Obes (Lond) 32, Suppl. 5, S66-S75.

32. Jacques PF, Sulsky SI, Sadowski JA, et al. (1993) Comparison of micronutrient intake measured by a dietary questionnaire and biochemical indicators of micronutrient status. Am J Clin Nutr 57, 182-189.

33. Bates CJ, Rutishauser IH, Black AE, et al. (1979) Long-term vitamin status and dietary intake of healthy elderly subjects. 2. Vitamin C. Br J Nutr 42, 43-56.

34. Jenab M, Slimani N, Bictash M, et al. (2009) Biomarkers in nutritional epidemiology: applications, needs and new horizons. Hum Genet 125, 507-525.

35. Bor MV, von Castel-Roberts KM, Kauwell GP, et al. (2010) Daily intake of 4 to 7 microg dietary vitamin B-12 is associated with steady concentrations of vitamin B-12-related biomarkers in a healthy young population. Am J Clin Nutr $\mathbf{9 1 ,}$ 571-577.

36. Hvas AM, Gravholt CH \& Nexo E (2005) Circadian variation of holo-transcobalamin (holo-TC) and related markers. Clin Chem Lab Med 43, 760-764.

37. Rock CL, Swendseid ME, Jacob RA, et al. (1992) Plasma carotenoid levels in human subjects fed a low carotenoid diet. J Nutr 122, 96-100.

38. Willett WC, Stampfer MJ, Underwood BA, et al. (1983) Vitamins A, E, and carotene: effects of supplementation on their plasma levels. Am J Clin Nutr 38, 559-566.

39. Sonnenberg LM, Quatromoni PA, Gagnon DR, et al. (1996) Diet and plasma lipids in women. II. Macronutrients and plasma triglycerides, high-density lipoprotein, and the ratio of total to high-density lipoprotein cholesterol in women: the Framingham nutrition studies. J Clin Epidemiol 49, 665-672.

40. Hodge AM, Simpson JA, Gibson RA, et al. (2007) Plasma phospholipid fatty acid composition as a biomarker of habitual dietary fat intake in an ethnically diverse cohort. Nutr Metab Cardiovasc Dis 17, 415-426.

41. Andersen LF, Solvoll K \& Drevon CA (1996) Very-long-chain $n-3$ fatty acids as biomarkers for intake of fish and $n-3$ fatty acid concentrates. Am J Clin Nutr 64, 305-311.

42. Hodson L, Skeaff CM \& Fielding BA (2008) Fatty acid composition of adipose tissue and blood in humans and its use as a biomarker of dietary intake. Prog Lipid Res 47, 348-380.

43. Baylin A, Kim MK, Donovan-Palmer A, et al. (2005) Fasting whole blood as a biomarker of essential fatty acid intake 
in epidemiologic studies: comparison with adipose tissue and plasma. Am J Epidemiol 162, 373-381.

44. Estruch R, Martinez-Gonzalez MA, Corella D, et al. (2006) Effects of a Mediterranean-style diet on cardiovascular risk factors: a randomized trial. Ann Intern Med 145, 1-11.

45. Mozaffarian D (2011) The great fat debate: taking the focus off of saturated fat. J Am Diet Assoc 111, 665-666.

46. Willett WC (2011) The great fat debate: total fat and health. $J$ Am Diet Assoc 111, 660-662.

47. Uauy R, Mize CE \& Castillo-Duran C (2000) Fat intake during childhood: metabolic responses and effects on growth. Am J Clin Nutr 72, 1354S-1360S.

48. Lowik MR, Hulshof KF \& Brussaard JH (1999) Food-based dietary guidelines: some assumptions tested for The Netherlands. BrJ Nutr 81, Suppl. 2, S143-S149.

49. WHO (1998) Obesity: Preventing and Managing the Global Epidemic. Report of a WHO Consultation on Obesity Geneva 3-5 June 1997. Geneva: WHO.

50. Novac O, Matasaru S, Tataru S, et al. (2009) Assessment of complications of excess weight in school-age children and adolescents. Rev Med Chir Soc Med Nat Iasi 113, 740-744.

51. Vyncke KE, Libuda L, De VT, et al. (2012) Dietary fatty acid intake, its food sources and determinants in European adolescents: the HELENA (Healthy Lifestyle in Europe by Nutrition in Adolescence) Study. Br J Nutr $\mathbf{1 0 8}$, 2261-2273.

52. Kabagambe EK, Baylin A, Allan DA, et al. (2001) Application of the method of triads to evaluate the performance of food frequency questionnaires and biomarkers as indicators of long-term dietary intake. Am J Epidemiol 154, 1126-1135.

53. Holick MF (2007) Vitamin D deficiency. N Engl J Med 357 , 266-281

54. Zhang R \& Naughton DP (2010) Vitamin D in health and disease: current perspectives. Nutr J 9, 65 .

55. Selhub J \& Paul L (2011) Folic acid fortification: why not vitamin $\mathrm{B}_{12}$ also? Biofactors 37, 269-271.
56. Pepper MR \& Black MM (2011) $B_{12}$ in fetal development. Semin Cell Dev Biol 22, 619-623.

57. Bjorke Monsen AL \& Ueland PM (2003) Homocysteine and methylmalonic acid in diagnosis and risk assessment from infancy to adolescence. Am J Clin Nutr 78, 7-21.

58. Remig V, Franklin B, Margolis S, et al. (2010) Trans fats in America: a review of their use, consumption, health implications, and regulation. J Am Diet Assoc 110, 585-592.

59. Hann CS, Rock CL, King I, et al. (2001) Validation of the Healthy Eating Index with use of plasma biomarkers in a clinical sample of women. Am J Clin Nutr 74, 479-486.

60. Newby PK, Hu FB, Rimm EB, et al. (2003) Reproducibility and validity of the Diet Quality Index Revised as assessed by use of a food-frequency questionnaire. Am J Clin Nutr 78, 941-949.

61. Weinstein SJ, Vogt TM \& Gerrior SA (2004) Healthy Eating Index scores are associated with blood nutrient concentrations in the third National Health And Nutrition Examination Survey. J Am Diet Assoc 104, 576-584.

62. Neuhouser ML, Patterson RE, King IB, et al. (2003) Selected nutritional biomarkers predict diet quality. Public Health Nutr 6, 703-709.

63. Gerber MJ, Scali JD, Michaud A, et al. (2000) Profiles of a healthful diet and its relationship to biomarkers in a population sample from Mediterranean southern France. $J \mathrm{Am}$ Diet Assoc 100, 1164-1171.

64. Vereecken C, Dohogne S, Covents M, et al. (2010) How accurate are adolescents in portion-size estimation using the computer tool Young Adolescents' Nutrition Assessment on Computer (YANA-C)? Br J Nutr 103, 1844-1850.

65. Bundeslebensmittelschlüssel (BLS) - German Nutrient Data Base (2011) http://bls.nvs2.de (accessed September 2011).

66. Deharveng G, Charrondiere UR, Slimani N, et al. (1999) Comparison of nutrients in the food composition tables available in the nine European countries participating in EPIC. European Prospective Investigation into Cancer and Nutrition. Eur J Clin Nutr 53, 60-79. 